\title{
The Dhimals - A Little Known Tribal Group of Sub-Himalayan West Bengal: Historical Perspectives
}

\author{
Subir Biswas \\ Department of Anthropology, University of North Bengal, Raja Rammohunpur, \\ Darjeeling 734013, West Bengal, India \\ Telephone: (0353) 2699015 (O) 2776322 (R) Fax: 2699001 (Univ.) \\ E-mail: gargisubir@gmail.com
}

KEYWORDS Dhimal. Tribe. North Bengal. Documentary Research

\begin{abstract}
The Dhimal of North Bengal had categorized as non-Aryan tribe by eminent scholars of preIndependent India like Hodgson, Dalton, Hunter, Risley and O'Malley. However, several years after Independence, they have been going through a non-recognition period simply by wiped out from Govt. census. Recently they have been classified as Other Backward Classes (OBC) of West Bengal. Even in terms of education, occupation or SocialCultural context they are very similar to tribal communities of West Bengal even primitive one. Therefore, they (Dhimals) demand for Scheduled tribe status instead of OBCs. The present paper is an attempt to identify almost all the documents on Dhimals, which has a historical importance in the field of Anthropological research, and also to conclude the status of Dhimals as per previous writings. The study is a type of documentary research; data have been collected from almost all secondary sources after scanning of existing literatures scattered in different forms as well as through retrospective search of non-printed sources. The sources have identified the Dhimals as a nonAryan Tribe, with distinguishable characteristics; though with some recent changes in cultural aspects, which is not so deviated that can exclude Dhimals from previous status.
\end{abstract}

\section{INTRODUCTION}

The Dhimal or Dhemal, a little known community of West Bengal, had been categorized as non-Aryan tribe before the independence. Eminent scholars like Hodgson, Dalton, Hunter, Risley, O'Malley and others identified Dhimals as Tribe, Aboriginal Tribe and so on. The pre-Independence Scholars like Bista, Gautam and ThapaMagar, as well as Regmi of Nepal and Deb Burman and Chaudhuri of India suggested the same regarding status of this forgotten ethnic group. Now, after a transitional non-recognition period by the Govt. they have been classified as Other Backward Class (OBC) of West Bengal. The history of study (or not to study) on Dhimals of India narrate the negligence for which the once non-Aryan tribe of British India having no reservation on any field, have to compete with others (the recognition as $\mathrm{OBC}$ is a recent one, though they are not satisfied with present status and demand the status of Scheduled Tribe instead of $\mathrm{OBCs}$ ). Because of the uneven competitions with dominant next door neighbours and others in respect of nation, push them much behind whether in the field of education, occupation or sociocultural context as a whole. A very few of them (thirteen in number) have crossed the border of Secondary education, and two of them are grad- uates. As per occupation they are cultivator, though the frequencies of labourers including agricultural labourer or in some extent tea garden labourer may not be overlooked. Now-adays Indian Dhimals are exclusively concentrated on Hatighisa and Maniram Gram Panchayet of Naxalbari Police Station under Darjeeling district of West Bengal, India. However sporadic occurrences of Dhimal population may have seen outside the above said areas but within Darjeeling district of West Bengal. The population figure, as enumerated after an extensive field work on this region, hardly touches the number 900 even today. The population figures as suggested (not enumerated but calculated after recall of some Dhimals without covering whole population) by amateurs in vernacular writings is not reliable in true sense. Even this diminutive group sometimes misleads as vanishing races by some amateurs. Though their counterpart of Nepal, which they have a marital relation and belongs to same (biological) population, have better numerical strength, socio-economic and educational attainment of their own. The Dhimals of Nepal receive much importance in various writings of Nepali scholars. On the other hand the Indian Dhimals have been neglected from Govt. and others in any field of development. Anthropological documents on Indian Dhimal yet to be 
receive; some sporadic documents by amateurs and some field based study by trained scholars in a part of Dhimal population may be available but all of them covering social-cultural-linguistics only and physical or demographical data on whole population is literally absent.

\section{MATERIALS AND METHODS}

The data were collected from different libraries of India and from website as well, hence, are mostly secondary in nature. The study may be regarded as documentary research and is a form of retrospective search from various sources like books, journals, census, gazetteers, news papers, website and so on. After collection of documents, scanning of existing literatures scattered in different forms were done keeping in mind the specific objectives of the study i.e. to understand the status of Dhimal from existing sources. After scanning, data was analyzed and filtered as per need of the study. Sometimes data were supplanted by primary data in conventional and metaform, directly collected from field by household survey, interviews and observations.

\section{RESULTS AND DISCUSSION}

The first identified study on Dhimal of this region may be attributed to English administrators for the sake of their administration, though scholarly attitude of the articles may not be overruled. As per present knowledge the first report in the form of monograph on Dhimal was written by Brain Houghton Hodgson (1847) entitled " $E s$ says the first on the Kocch, Bodo and Dhimal Tribes", printed by J. Thomas of Baptist Mission Press at Calcutta. The monograph was divided into three parts: Part-I: Vocabulary, Part-II: Grammar and Part-III: Location, Numbers, Creed, Customs, Condition and Physical and Moral Characteristics of the People. Among them the third one is very much important to an Anthropologist and also to study the present objectives.

Later on Hodgson published the third part in 1849 in Journal of Asiatic Society, vol-18 without any change from original one entitled "On the Origin, Location, Numbers, Creed, Customs, Characters and Condition of the Kocch, Bodo and Dhimal People, with a general description of the climate they dwelt in" (Hodgson 1849). Again Trubner and Co. in 1880 published the same orig- inal collection of 1847 in the book entitled "Miscellaneous Essays relating to Indian Subjects, Vol-I" (Hodgson 1880).

All of the articles identified Dhimals as Aboriginal Tribes of this region. Hodgson identified their religion as the religion of nature, or rather, the natural religion of man have neither temple nor idol; their cultivation as shifting cultivation; and "this race assure him that they once had chiefs when they dwelt as a united people in Mourang". Hodgson enumerated the number of Dhimals between Konki and Dhorla as below 15,000 souls. Hodgson stated that Dhimal “...do not now exceed 15,000 souls, are at present confined to that portion of Saul forest lying between the Konki and the Dhorla or Torsha, mixed with the Bodo but in separate villages and without intermarriage". According to Hodgson the Meches or Bodos and Dhimal tribes are of the same race, however, comparison of language does not support so close connection, he added. He stated that "...but it is difficult to suppose the Bodo and Dhimal languages other than primitive". He also stated that the Dhimals are ".....nomadic cultivators of wild. For ages transcending memory or tradition, they have passed beyond the savage or hunter state, and also beyond the herdsman's state, and have advanced to the third or agricultural grade of social progress, but so as to indicate a not entirely broken connection with the precedent condition of things.... They never cultivate the same field beyond the second year, or remain in the same village beyond from four to six years". He again identified the barter system for the few things which they require and do not produce themselves. The religion, as identified by Hodgson, is very much different from Hindu as they have neither temples nor idols. "Altogether, their religion belongs to the same primitive era as their habits and manners", Hodgson added.

Latham (1859) in 'Descriptive Ethnology' identified the place of Dhimals as unfavourable with full of malaria, though, he stated "...yet the Dhimal, the Bodo, and others thrive in it, love it, leave it with regret". He believes that Dhimals are separated from Bodos as language, pantheons, marriage ceremony, funerals even festivals of the two are very much different. Latham also identified Hodgson's work as "a model of an ethnological monograph".

After that all writings are more or less influenced by and borrowed data from Hodgson's 
writings. Among them the writing of Edward Twite Dalton (1872) may be mentioned. Dalton in his 'Descriptive Ethnology of Bengal' identified Dhimals as tribe of Assam valley, clubbed with the Kacharis or Bodo and Mech; and stated " Hodgson describes the Bodo and Dhimal tribe as of the same race, and there appears no reason for separating them in a work of this nature, as their customs, religion, etc. appear nearly identical".

W. W. Hunter (1876) in "Statistical Account of Bengal" stated that census report distinguishes between these peoples (Dhimals and Meches or Bodos), and returns the number of Dhimals at 873. Later on he wrote a brief note on Dhimal culture which are, as per Hunter, is a condensed form of Hodgson's work.

Sannial (1880) when studied Dhimals found hunting and pastoralism as their main source of occupation. He also stated that the village was headed by a headman called 'Mondal' and magico-religious practices by Dhami, Deushi and Ojha.

Dhimal again finds their position in $\mathrm{H}$. H. Risley's "The Tribes and Castes of Bengal" where Risley pointed out that "Dhimal, Dhemal, Maulik, a non-Aryan tribe of the Darjeeling and Nepal Terai .... belong to the same main stock with Kocch ... rapidly losing their tribal identity by absorption into the large heterogeneous Rajbansi caste". He also pointed out a marked advanced direction towards Hinduism from nature worship. Risley opined that "they seem likely to disappear altogether as a separate tribe within the next generation" (Risley, 1891).

Bandyopadhyay (1895) in his Darjeeling Probasir Patra stated that the cultural aspects of Meches and Dhimals are more or less same, even the folklore, Bandyopadhyay collected, indicates the same origin of Dhimals with Koch and Meches.

O'Malley (1907) in his 'District Gazetteers of Darjeeling' classified Dhimals as non-Hinduized Koch or Rajbansi and identified their (Dhimal) habitat as "marshy tract, formerly covered by dense malarious jungle, in which aboriginal tribes of Meches, Dhimals and Koches burnt clearings and raised their scanty crops of rice and cotton on a system, if system it can be called, of nomadic husbandry".

Grierson (1926) in 'Linguistic Survey of India' classified Dhimal language as 'Eastern Pronominalized group' of 'Pronominalized Himalay- an Group' under 'Tibeto Himalaya Branch' of 'Tibeto-Burman subfamily' which may be categorized under 'Tibeto-Chinese group'. He also stated that "In the Pronominalized group the influence of the ancient Munda language is far more apparent". Endle (1911) placed Dhimals under Northern groups of Kachari family along with Kachari, Rabha, Mech, Koch and others. Later on Das (1978) examined the same and opined the possibility of same ethnological relationship between these tribes.

Deb Burman and Chaudhuri (1999) identified Dhimals as a backward community having tribal origin and "acceptance of Mallick or Maulik title as well as adoption of Hindu religious practices is the stereotype for not considering them tribe. But the strong argument in favour of noninclusion of the Dhimals in the list of Scheduled Castes and Scheduled Tribes of India could be their migration to the neighboring countries like Nepal and Bhutan at the time of enumeration", they added.

Roy (1999) in his unpublished M. Phil. dissertation noted the prevalence of 'barter system' in Dhimal community of this region. Some recent studies on vernacular language (Bandyopadhyay 2004; Chakladar and Biswas 2004; Bandyopadhyay 2004) also exhibit the above stated characteristics, many of which are typical tribal characters of their own.

Moitra (2004) identified a close affinity between Dhimal and Toto languages; he even calculated the separation of Toto from Dhimal, by grutochronological analysis, as 800-1200 AD. Royburman (1959) in his thesis on Toto also highlighted the same by stated "there is one variant of Toto myth of origin which refers to the Dhimals as the mother group. (Toto) assess the very close affinity exists between the language of the Totos and the Dhimal" but, he added, "as, however, I do not possess any scientifically assessed data, I do not propose to enter into the realm of social psychology". King (1994) after his linguistic survey opined that its (Dhimal) closest relative appears to be Toto (IIAS 2007).

Among Nepali scholars who have done ethnographical and social-cultural aspects on $\mathrm{Ne}$ pali Dhimals the following names is of great important. Bista (1980) identified Dhimals as nomadic, practicing shifting cultivation until some times ago, they have traditional village councils with a headman called Deonia and the priest who presides over all of the religious function is called 
Dhami. Regmi (1991) identified a total of 13 exogamous patrilineal clans and 11 sub-clans within the population. Gautam and Thapa-Magar (1994) also classified Dhimals as Tribes in their work "Tribal Ethnography of Nepal". In a recent work Bisht and Bankoti (2004) also followed the same trend by placing Dhimals on "Encyclopedic Ethnography of the Himalayan Tribes".

There is a continuous census enumeration on Dhimal population (or sometimes language spoken) up to 1951 except 1941 . The 1872 census identified Dhimals as Aboriginal Tribe. The 1891 census headed by O'Donnell identified Dhimals as Forest and Hill Tribes as well as Agriculturalist by occupation. But next census headed by E. A. Gait classified Dhimals as Hindu by religion; even the census stated that they (Dhimals) often called themselves as Rajbansi. The same trend was carried over by 1931 census headed by Porter. The 1961 census has lost Dhimal data but even it stated Dhimals as Aboriginal tribes as per 1872 .

After that no single census (1971, 1981, 1991, 2001) have been drawing any traces on Dhimal community or languages, though some very small population even with single household was being considered for the study.

\section{OBSERVATION}

From the writings of eminent scholars like Hodgson, Dalton, Hunter, Risley, O'Malley, different census headed by O'Donnell and Gait, different eminent Nepali and Indian scholars like Regmi, Bista, Gautam and Thapa-Magar, Deb Burman and Chaudhuri, it may be conclude that Dhimals may be regarded as Tribe with its distinctive characteristics as per secondary data collected for the purpose. It is basically due to inattention of Government (or Census) side, not to provide the status or even enumerated figure for a long time after independence.

Again after the introduction of The Constitution (Scheduled Caste and scheduled Tribe) Order 1950 or even The Scheduled Caste and Scheduled Tribe list (modification) Order 1956, the Dhimals can't find them in the list of Scheduled Tribe, though there was clear indication of tribal status of Dhimals on first set of writings specially by Hodgson, Dalton, Risley and so on. This may be attributed because of no trace of Dhimal during 1941 census.

The Government Census and gazetteers may have a greater importance on present status of Dhimals of India. The recognition as aboriginal tribes throughout first couple of census and not recognized them as Scheduled Tribes after The Constitution Scheduled Castes and Scheduled Tribes order 1950 or even Modification order 1956, is somewhat confusing.

The non inclusion of Dhimal in the census, as per scholars, may also be attributed to Dhimals, who supposed to present themselves as other than Dhimals ( after the influence of dominant neighbour Rajbansis, they might described themselves as orthodox Hindu) or due to error of untrained enumerator, to classify Dhimals other than Dhimals without knowing population identity. Whatever it may be, the non inclusion of Dhimal in 1941 census mostly attributed to non inclusion of Dhimals in Scheduled Castes and Scheduled Tribe list of India Government. The identification of Dhimals as OBC's in recent days is again a controversial one; the poor, economical and educational backward community finds it difficult to compete with their counterpart of same status as per Government.

However lack of scientific study on Dhimal can't permit us to a concrete conclusion about status of Dhimal and it require a detailed anthropological study on the Dhimals of North Bengal. Though, it may conclude that the present status of Dhimal is also not a scientific one as per available data, and it also requires proper data to supporting the present status instead of tribes as per eminent scholars of this field.

\section{ACKNOWLEDGEMENT}

The author wish to acknowledge University Grants Commission for financial assistance; Prof. S. R. Mondal and Prof. S. Pal for their kind guidance.

\section{REFERENCES}

Bandyopadhyay Sekhar 2004. Dhimal. Kolkata: Centre for Folklore and Tribal Culture, Govt. of West Bengal.

Bandyopadhyay Tarapada 1895. Darjeeling Probasir Patra. In: K. Chaudhuri (Ed.): Derjellinger Itihas. 2005.Kolkata: Dey's Publishing, pp. 141-170.

Bisht NS, Bankoti TS 2004. Encyclopedic Ethnography of the Himalayan Tribes (Vol-I). Delhi: Global Vision Publ. House.

Bista Dor Bahadur 1980. People of Nepal. Kathmandu: Ratna Pustak Bhandar.

Chakladar Paritosh, Biswas Ratan 2004. Dhimal Bhasa. In: Ratan Biswas (Ed.): Uttar banger Bhasa: A Collection of Essays on the Languages of North Bengal. Kolkata: Baiwala, pp. 466-483. 
Dalton Edward Twite 1872. Descriptive Ethnology of Bengal, Calcutta: Govt. Printing, Reprint. 1973. Tribal History of Eastern India. Delhi: Cosmo Publications.

Das ST 1978. The People of the Eastern Himalaya. New Delhi: Sagar Publication.

Deb Burman, Prasenjit and Buddhadeb Chaudhuri 1999. The Dhimals: A Little Known Tribal Community. Occasional Paper No. 9, Dr. Ambedkar Chair in Anthropology, Deptt. of Anthropology, Calcutta University.

Endle 1911. The Kacharis, cited on ST Das 1978. The People of the Eastern Himalaya. New Delhi: Sagar Publication.

Gautam Rajesh, Thapa-Magar Ashok K 1994. Tribal Ethnography of Nepal (vol-1). Delhi: Book Faith India.

Grierson George Abraham 1926. Linguistic Survey of India, Vol-III Tibeto-Burman Family, Part-I. Calcutta: Govt. of India, Central Publication Branch.

Hodgson Brian Houghton 1847. Essay the first on the Kocch, Bodo and Dhimal Tribes, Calcutta: Baptist Mission Press.

Hodgson Brian Houghton 1849. On the Origin, Location, Numbers, Creed, Customs, Characters and Condition of the Kocch, Bodo and Dhimal People with a General Description of the Climate they dwell in, Journal of the Asiatic Society, 18: 702747.

Hodgson Brian Houghton 1874. Essays on the Languages, Literature and Religion of Nepal and Tibet (Together with further papers on the Geography Ethnology and Commerce of those Countries), Reprint, 1971, Varanasi: Bharat-Bharati.

Hodgson Brian Houghton 1880. Miscellaneous Essays relating to Indian Subjects, vol-II. London: Trubner and Co.

Hunter William Wilson 1876. Statistical Account of Bengal, Vol-X: District of Darjeeling, Jalpaiguri and State of Kuch Behar. London: Trubner and Co.

India Census 1881. Census of India, 1881. Statistics of Population, Vol-II, Calcutta: Govt. Printing Press.

India Census 1891. Census of India, 1891, Vol-V, The Lower Provinces of Bengal and their Feudatories. Calcutta: Bengal Secretariat Press.
India Census 1901. Census of India, 1901, Vol-VI A, The Lower Provinces of Bengal and their Feudatories. Calcutta: Bengal Secretariat Press.

India Census 1911. Census of India, 1911, Vol-V, PartI, Calcutta: Bengal Secretariat Press.

India Census 1921. Census of India, 1921, Vol-V, Bengal, Part-II, Calcutta: Bengal Secretariat Press.

India Census 1931. Census of India, 1931, Vol-V, Bengal and Sikkim, Part-II. Calcutta: Central Publication Branch.

India Census 1941. Census of India, 1941, Vol-IV, Bengal. Delhi: Manager of Publication.

India Census 1951. Census of India, 1951, West Bengal District Handbook: Darjeeling. Alipore: W.B. Govt. Press.

International Institute of Asian Studies (IIAS) 2007. Dhimal, Retrieved August 18, 2007, from < http:/ /www.iias.nl/himalaya/?q =dhimal $>$

King John Timothy 1994. Picking up where Hodgson left off: Further notes on Dhimal, Linguistics of the Tibeto-Burman Area, 17(2): 121-132.

Latham RG 1859. Tribes and Races (vol-1). Reprint 1983, .Delhi: Cultural Publishing.

Moitra Mritunjoy 2001. Uttarbanger Biluptoprai Janojati: Dhimal. In: Ratan Biswas (Ed.): Uttarbanger Jati-O-Upojati. Calcutta: Punascho, pp. 237-278.

O’Malley LSS1907. Bengal District Gazetteers: Darjeeling. Reprint 1999. New Delhi: Logos Press.

Regmi Risikesh Raj 1991. The Dhimals: Miraculous Migrants of Himal (An Anthropological Study of a Nepalese Ethnic Group). Jaipur: Nirala Publication.

Risley Herbert Hope 1891. The Tribes and Castes of Bengal (vol-1). Reprint 1998. Calcutta: Firma KLM Pvt. Ltd.

Roy Ranjit 1999. The Dhimals-A Little Known Community of Sub-Himalayan Bengal (An Ethnographic Overview). M. Phil. Dissertation (Unpublished), Silliguri: Centre for Himalayan Studies, North Bengal University.

Royburman Bikram Keshari 1959. Dynamics of Persistence and Change of a Small Community: The Totos. Ph. D. Thesis (Unpublished), Calcutta: University of Calcutta.

Sannial Hari Mohon 1880. History of Darjeeling in Bengali. In: Kamal Choudhuri (Ed.): Darjeeliner Itihas. 2005. Kolkata: Dey's Publishing, pp.13-98. 